For submission to International Journal of Disaster Risk Reduction, 19 July 2016.

Resubmitted October 24, 2016.

\title{
Perceptions of Earthquake Early Warnings on the U.S. West Coast
}

\author{
Peter T. Dunn ${ }^{* a}$, Alicia Y.E. Ahn ${ }^{\mathrm{b}}$, Ann Bostrom ${ }^{\mathrm{b}}$, John E. Vidale ${ }^{\mathrm{c}}$ \\ a Department of Urban Design and Planning, University of Washington, Seattle, WA 98195, USA \\ ${ }^{\mathrm{b}}$ Evans School of Public Policy and Governance, University of Washington, Seattle, WA 98195, \\ USA \\ ${ }^{\mathrm{c}}$ Earth and Space Sciences, College of the Environment, University of Washington, Seattle, WA \\ 98195, USA \\ * Corresponding author. Email: ptdunn@uw.edu.
}

Key words: Earthquake early warning, risk perception, risk communication, hazard preparation, willingness to pay

\section{Abstract}

Earthquake early warning systems can provide seconds to minutes of lead time by alerting people that an earthquake has started and shaking is coming, enabling them to take protective action. To examine how earthquake early warnings might be received on the U.S. West coast, we conducted surveys of residents in the west coast states of Washington, Oregon and California $(\mathrm{N}=2,595)$ through Google paywall intercept surveys administered in three rounds between September 2014 and September 2015. A majority of residents in all states $(61 \% \mathrm{WA}, 54 \% \mathrm{OR}, 70 \% \mathrm{CA})$ have personally experienced an earthquake. Those who have experienced an earthquake perceive higher risk and greater potential for effectively reducing that risk with earthquake early warning. Although respondents feel that federal and local government should pay for earthquake early warning, almost two-thirds report being willing to pay something for "an Earthquake Early Alert app on [their] smartphone or personal computer." Median willingness to pay per month is $\$ 1$. Perceived risk, perceived effectiveness of earthquake early warning, and anticipated or experienced emotional responses to earthquakes influence judgments of and preferences for earthquake early warning, although personal experience of earthquakes conditions these influences. Further, highly visible mass media communications such as the New Yorker article "The Really Big One" and the movie "San Andreas" increase earthquake risk perceptions. Overall, interest in and support for earthquake early warning on the U.S. West Coast appears strong.

\section{Acknowledgments:}

Funding from NSF EAR 1331412. We gratefully acknowledge very helpful contributions to the survey design from Jim Goltz, David Johnston, and Michael Lindell, and our colleagues in the M9 research team at the University of Washington. All errors are ours alone.

Preliminary results for September 2014 data presented at the EEW conference in Berkeley, September 2014 data presented at the 2015 Natural Hazards Workshop. Preliminary results for the paper presented at the 2015 Society for Risk Analysis annual meetings in Crystal City, Virginia. 


\section{Introduction}

Developments in science and technology for earthquake early warning (EEW) systems are increasing the feasibility of short advance warnings ${ }^{1}$ of the arrival of shaking from an earthquake. Although the ability to predict earthquakes remains elusive, EEW systems take advantage of the difference in speed between the faster compression wave (primary or P-wave) detectable by seismic sensors and the slower surface wave (secondary, or sheer, S-wave) that causes damage, and other factors, to provide an alert before shaking begins. Earthquake early warnings can give a few seconds to minutes of advance warning of the shear waves that cause damaging shaking. This can allow enough time for people to move out of risky locations, to secure dangerous objects, or to put critical systems into a safe mode - in other words, enough time to reduce the risk from earthquake hazards. For an earthquake hazard to pose a risk requires that people be exposed and vulnerable; EEW can reduce exposures and vulnerabilities. Some infrastructure can be connected to EEW systems to provide an automatic response, while people can be notified through their mobile phones, internet, or other media. Early warning systems hold great promise (e.g., Allen 2001, 2011; Goltz 2002, 2003; Heki 2011; Wenzel et al., 2001; Yamasaki 2012), with evidence of successful prevention and mitigation of damage from earthquakes for those EEW systems that have been deployed around the world (Allen 2011; Fujinawa and Nodi, 2013, Hoshiba, 2014; Hoshiba et al., 2011). Further, people's awareness of such systems should also promote their consideration of other earthquake preparations. In Japan, increased awareness of EEW has led to more effective protective action (e.g., Fujinawa and Nodi, 2013, Hoshiba, 2014)

While warning and disaster response capability in Washington state has been investigated (e.g., Johnston et al. 2007), to date there has been little research in the U.S. on public receptiveness or demand for EEW, or on how best to deploy EEW alerts to public audiences. A notable exception is the TriNet reports in 2001 (e.g., Riopelle et al. 2001; Goltz 2003). Lessons from other warning system research pertain (e.g., Goltz and Mileti 2011; Leonard et al., 2008; Mileti and Sorenson, 1990; NRC 2010, 2013), but do not suffice to guide the design and evaluation of EEW systems. Little is known regarding public willingness to support development of or pay for EEW on the U.S. West Coast, or about the correlates of such support. In this paper we report the results of surveys that begin to address this gap. In the next sections we introduce the context of the study, then our hypotheses and methods.

\subsection{Background and Model}

Earthquake hazards pose a catastrophic risk to vulnerable urban areas, as devastation from events in the last decade demonstrates (UNISDR 2015). Earthquakes are a particularly difficult hazard to prepare for. Unlike weather hazards, many of which can be foreseen days before their arrival, earthquakes arrive nearly immediately. Given the absence of an approach period before the hazard event in which communities and households can make last-minute preparations, communities hoping to minimize the destruction and disturbance to everyday life that an earthquake threatens require a constant state of preparedness. However, the relative rarity of major earthquakes compared to, say, winter storms, puts them out of mind for most people, potentially reducing motivations to prepare. Hence the challenge for emergency managers charged with preparing communities for seismic hazards is to overcome perceptions that earthquakes pose no serious risk, or that there will be time to prepare later.

On July 20, 2015 the New Yorker magazine published "The Really Big One" by Kathryn Schulz, a journalist and author who once had lived in Oregon. Like the rest of the U.S. Coast, Oregon is at risk

${ }^{1}$ A distinction can be drawn between alerts and warnings: "Alerts are designed to indicate that something significant has happened or may happen. Warnings, which typically follow alerts, provide more detailed information, indicating who is at risk, where the risk resides, who is sending the warning message, and what protective actions need to be taken" (NRC 2011:6). In theory, an EEW system could be used for both alerts and warnings. 
from a Cascadia subduction zone earthquake. Schulz paints a gripping scene of devastation in the face of West Coast vulnerabilities to such an event, including reference to a FEMA Director's statement that "Our operating assumption is that everything west of Interstate 5 will be toast." Although this statement pertained to what FEMA assumes in a worst-case scenario planning exercise, not to general expectations, it was widely repeated on the University of Washington campus in reference to the article and to the potential for a magnitude 9 (M9) Cascadia subduction zone event. Schulz's piece went viral. Her piece also highlights the potential of early warning, commenting that the Pacific Northwest has no earlywarning system. Spurred in part by "The Really Big One," on February 2, 2016, the U.S. White House held an Earthquake Resilience Summit. The summit opened with the announcement of President Obama's Executive Order Establishing a Federal Earthquake Risk Management Standard, followed by announcements of support for ShakeAlert, an earthquake early warning (EEW) system being developed for the U.S. West Coast collaboratively by the University of Washington, University of California Berkeley, Caltech, University of Oregon, the Moore Foundation and the United States Geological Survey (Given et al 2014).

The technical engineering challenges of EEW are daunting, but just as important are the social questions about how EEW fits into the overall preparedness of individual households and communities. Effectively reducing risks from hazards such as earthquakes requires advances in measuring, modeling, and forecasting individual and social behaviors, as well as better understanding built and natural environments. How risks are interpreted and what actions people take to protect themselves from, or in response to, hazardous events depend on cognitive, emotive, social and institutional contexts, as well as on their natural and built environments (Becker et al., 2012a, 2012b; Eiser et al. 2012; Tierney 2014). In this earthquake early warning (EEW) systems resemble other forecast and warning systems. Such systems include not only technologies to detect threats, their reliability, and the length of time needed to achieve accuracy in forecasts and predictions, but also elements such as: reliance on human mediation; channels for issuing warnings; familiarity and institutionalization of warning procedure; settings in which systems are used; and system goals and objectives (Bostrom et al. 2016; Morss et al. 2015; Ropielle et al. 2001).

The successful implementation of ShakeAlert requires the active participation of institutions and individuals. They must first be aware of EEW and the underlying seismic risk it attempts to mitigate, then access the appropriate EEW technology, and then be prepared to take appropriate action when an alert is received. All of these actions are just one type of preparation that emergency managers hope that households will take in response to risks posed by earthquakes and other hazards.

To develop a better understanding of public perceptions of earthquake early warning and earthquake risks on the U.S. West Coast, we conducted a series of short surveys in August/September 2014, June 2015, and September 2015. Our data are collected from the Western United States (CA, OR, WA), with the last two waves of the survey conducted only in Washington. Washington State hazards have been the subject of numerous research projects in the social and behavioral sciences (e.g., Houghton et al. 2009; Johnston et al. 2002, 2005), and provide an excellent context for advancing risk and hazard research in this context. Our research replicates and extends prior EEW research in California (e.g., the TriNet reports-Riopelle et al. 2001; Tierney 2000).

Prior research on hazard and risk perception and decision making supports many of the tenets of the Protective Action Decision Making (PADM) model by Lindell and colleagues (Lindell and Perry 2012). According to PADM, protective actions result from social and physical (hazard) cues, forecasts and warnings, and appraisal processes (i.e., interpretive or evaluative processes), as well as the characteristics of message recipients (e.g., prior experiences) and the contexts in which they find themselves making protective action decisions (Figure 1). 


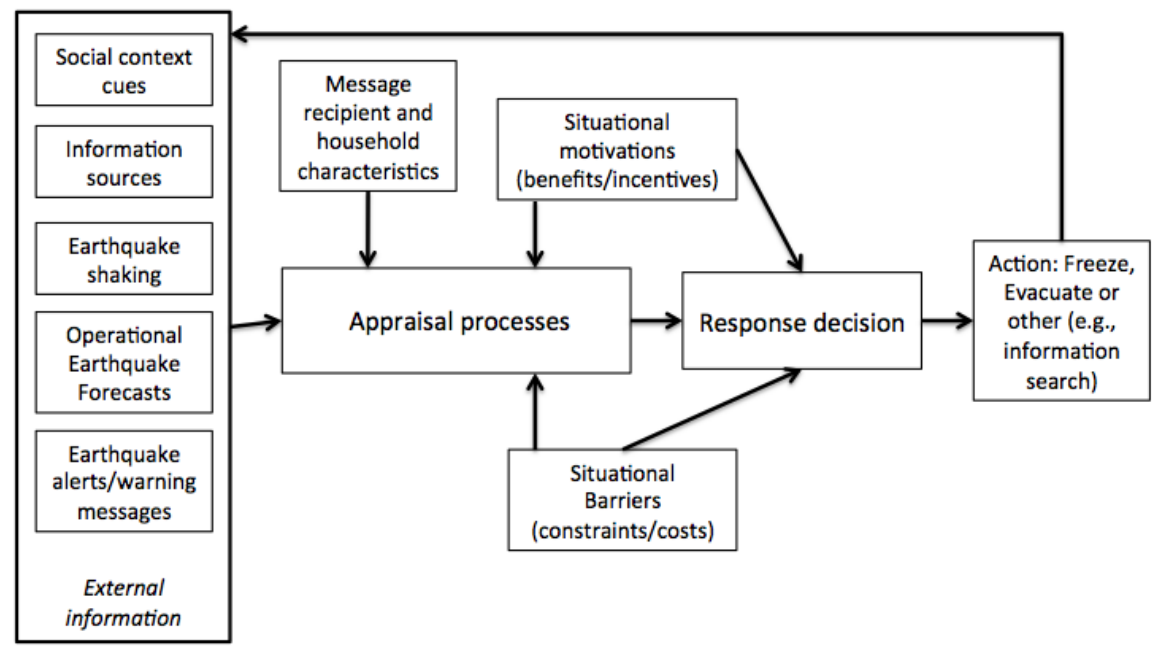

Figure 1. Adapted from Lazo et al. (2015), based on Lindell and Perry (2012).

A more individualistic theoretical framing is provided by health risk communication theories such as the Extended Parallel Process Model (or fear management model - Maloney et al 2011, Witte 1992) that emphasize how perceived threat, perceived efficacy (perceptions of if one is able to take action effectively, or how effective such action will be), and emotional responses (e.g., fear) determine how people act in response to health risk communications. Although recent assessments raise some questions about the fear management model, they also provide considerable evidence that perceived threat, perceived efficacy and emotional responses shape risk responses (e.g., Tannenbaum et al 2015).

\subsection{Hypotheses}

Our specific research questions for this paper are:

- How aware and concerned about earthquakes are U.S. West Coast residents? What are their prior experiences and expectations? How prepared are they?

- Are U.S. West Coast residents willing to invest in better preparations for and responses to earthquake hazards in Washington?

- Do U.S. West Coast residents expect that earthquake warnings with only seconds to minutes of advance notice can help protect them?

Our broader research aims include informing the design of EEW, and improving models of risk interpretation and action for low-probability high-consequence risks.

In this study we examine what influences individuals' personal commitment to prepare for earthquake hazards, as measured by their willingness to pay (WTP) in dollars for an EEW mobile app. Based on models of individual protective action, we expect the perceived value (or WTP) of a protective measure such as earthquake early warning to be influenced by (a) perceptions of external factors such as the risk of experiencing a seismic hazard (threat), (b) perceptions of benefits (i.e., efficacy) and costs of acting on EEW, and (c) message recipient characteristics, including earthquake experience, earthquake or all-hazard preparation experience, earthquake-related knowledge, and demographic characteristics.

We hypothesize that those who perceive themselves as being more likely to experience an earthquake will be willing to pay more for EEW. Similarly, we expect a perception of being at risk of being harmed by an earthquake will also be associated with higher WTP. These perceptions are themselves influenced by several factors. A trope in seismic risk discussions is that earthquakes don't kill people, buildings do (Hough and Jones, 2002; see also Spence and So, 2009, cf Johnston et al., 2014). Context matters; people who live in urban settings are more vulnerable by this measure, all else equal, and so may feel more at risk than those living in other settings. Also for this reason we posit that people may see structural mitigation as more important and more effective than EEW. We expect perceptions of 
greater EEW benefits and lower EEW costs also to be associated with greater WTP. For example, if people see investments in structural mitigation and early warning as trading off against one another, they may prefer that public protection expenditures go toward structural mitigation in lieu of funding EEW, in which case this would decrease their willingness to pay for EEW. Those who expect EEW to be effective are hypothesized to have a higher WTP.

In addition to these external factors and the perceived costs and benefits of EEW, we expect several individual characteristics to influence WTP. We hypothesize that past personal experience of an earthquake will influence WTP in a positive direction. Hazard experience appears to be associated with risk perception, as one might expect (Demuth 2015). To assess the degree to which different types of experience influence seismic risk preparedness preferences, we also examine whether the strength or type of personal experience influences WTP. We consider directness of experience (from none to vicarious/narrative to direct personal exposure) as well as actual or anticipated emotional response to experience. Actual or anticipated emotional response will be important if it is used heuristically (i.e., instead of analysis) to assess risks, benefits, or costs of earthquakes and earthquake early warnings (Finucane et al., 2000; Slovic et al., 2004; also Keller et al., 2006). At the same time, an individual who is prepared for hazards is likely to be more open to a variety of preparedness options, including an early warning system. Greater risk perception for earthquakes is associated with an increase in protective responses in prior studies (Becker et al., 2012a, b; Lindell and Perry, 2000), though this may be mediated by knowledge (Bourque et al., 2012). Greater knowledge has been shown to predict better preparedness (Paton et al 2015). We therefore hypothesize that hazard preparation levels and knowledge are positively associated with WTP for an early warning system.

\section{Methodology}

\subsection{Survey}

Our survey design is informed by open-ended interviews conducted with students and professionals involved in earthquake-related research, prior EEW research (e.g., Riopelle et al. 2001) and other prior research on how individuals understand earthquake information and other hazard forecasts, warning and mitigation information, as well as how this influences their preparedness (e.g., Becker et al. 2012a b ; Lindell \& Perry 2000; Lindell et al. 2009, 2015, 2016; Morgan et al. 2002; Wood et al. 2012a). The survey was administered by Google Consumer Insights as a paywall intercept survey. Google offers Internet users access to premium content on partner websites in exchange for their participation in the survey. According to Google's own research (McDonald et al., 2016), their samples more accurately represent the U.S. Internet population (which includes $87 \%$ of the U.S. population) than other Internet or telephone survey methods. Although Internet users are younger, wealthier, and more educated than the population at large, Google provides estimates of demographic variables and inferred sample weights that help mitigate these biases.

Surveys were administered in the West Coast states California, Oregon, and Washington in three different rounds: September $2014(\mathrm{n}=1204)$, June $2015(\mathrm{n}=418$, Washington only), and September 2015 ( $\mathrm{n}=973$, Washington only). Google limits each survey to 10 questions, with further constraints on question length and type. We used several survey versions with different combinations of 10 questions to collect data on a total of 14 questions (see Appendix).

Each survey begins by asking if the respondent has ever experienced an earthquake. Depending on the survey, either respondents who answer "yes" or those who answer "no" to this initial screening question then continue on to the survey, while the others are dropped. Response counts for this initial screening question are therefore much higher than the sample sizes reported above. Google provides data only for completed surveys; respondents who drop out before answering all 10 questions are not included. 


\subsection{Measures}

Each survey question measures one of our variables of interest. Except where noted, respondents can select either one (forced choice) or all ("check all that apply") of multiple response options. We measure seismic risk perception with three questions: (1) "How likely are you to experience an earthquake in the next year?" (5-point scale, response order randomly reversed: Likely (more than 66\% chance); About as likely as not (33\% to 66\% chance); Unlikely (less than 33\% chance);Very unlikely (less than 10\% chance); Extremely unlikely (less than 1\% chance)); (2) "How likely do you think it is that an earthquake will harm you in the next year?" (same response scale as previous); and (3) "When do you think the next earthquake is likely to affect your community?" (4-point response scale, order randomly reversed: Not within your lifetime; Within your lifetime; Within the next 10 years; Within the next year). The first of these measures perceived exposure to the hazard, whereas the other two measure tap into perceptions of vulnerability.

Perceptions of the effectiveness of EEW systems are measured by respondents' agreement with the statement "I would be better able to protect myself from earthquake risks, including death, with an earthquake early alert (a few seconds to minutes of warning)" (4-point response scale, order randomly reversed: Strongly Disagree, Disagree, Agree, Strongly Agree). In some surveys, respondents are also asked whether they think injuries will be "more," "less," or "about the same" with EEW. The level of agreement with the statement, "Earthquake hazard mitigation, such as reinforcing buildings, reduces the risk of death from earthquakes." is used to measure whether those who view other types of mitigation as effective are less likely to support EEW. Respondents re asked whether they think the "\$17 million a year" that EEW would cost should be paid for by the federal government, state and local government, forprofit organizations, non-profit organizations, or none of the above, in any combination. We expect that a belief that any of these sources should pay for EEW may influence personal WTP.

Respondents who answer that they have personally experienced an earthquake are also asked to type the date and location of their most recent earthquake experience in a text box. In the June 2015 survey, we also ask if respondents have seen the movie "San Andreas" (in wide release at that time) or any other earthquake movie as a measure of vicarious earthquake experience. Similarly, in the September 2015 survey we ask if respondents are familiar with the July 2015 New Yorker article "The Really Big One." We also examine the affective dimension of earthquake experience by asking about the actual or anticipated emotional response to being in an earthquake (6-point response scale, order randomly reversed: No reaction / not felt; Very little reaction; Excitement; Somewhat frightened; Very frightened; Extremely frightened).

A question about behavioral response to an earthquake asks what respondents did or expect they would do in an earthquake. To measure knowledge of earthquakes, respondents are asked to identify which (if any) of five earthquake-related topics they have heard of (plus a sixth - the New Yorker article - in the September 2015 survey). Emergency preparedness is measured by asking respondents which of five household emergency preparation activities they have made; home earthquake insurance is included as a sixth preparation in some of the surveys (over the year, Google increased the number of options allowed for such questions).

The survey uses individual willingness to pay as a measure of personal protective action and of support for EEW systems. Respondents are asked to type a number in response to the question "What is the most you would be willing to pay per month for an Earthquake Early Alert app on your smartphone or personal computer?" Answers greater than $\$ 100$ or less than $\$ 0$ return an error message and prompt the respondent to provide a different answer. Measuring WTP is known to be difficult, especially in an environment like this survey that does not address available resources and tradeoffs (Jones-Lee et al.,1985; Savage, 1993). Bounding the responses for the WTP question is one strategy for dealing with large variances in the responses. Our survey constrains the responses to a specific purpose of the payment, i.e., a mobile application. The WTP data that we report are therefore potentially anchored in the context of the market for mobile apps, which are generally free or very cheap. Asking about willingness to pay a surcharge on a phone bill might generate different responses, for example. Although the absolute 
numbers provided are therefore likely to be unreliable, they should still provide a fair indication of respondents' relative willingness to pay.

Google provides estimated demographic characteristics for each respondent, including gender; type of location (rural, suburban, urban); income (in six categories); and age (in six categories). Google also informed us after the fact that a small proportion (generally under 15\%) of survey respondents in later surveys may have taken the survey on a dedicated Google survey app. This is also reported in the data. Even though we did not expect this to influence WTP for EEW, because of potential concerns about self-selection into the mobile survey app we control for this in our models.

\subsection{Analysis}

Survey responses are transformed for regression analyses. Responses to several survey questions are treated as ordinal variables. For example, "agreement" responses are coded from 0 (strongly disagree) to 3 (strongly agree), and income is represented by integers ranging from 0 (annual income less than $\$ 25,000)$ to 5 (annual income of $\$ 150,000$ or more). For the question on affective response to earthquake experience, we create separate dummy variables for four sets of responses: (i) "excited," (ii) "somewhat frightened," and (iii) "very frightened" or "extremely frightened", plus a dummy for (iv) "little reaction" or "no reaction/not felt" responses, which serves as a base case.

For the familiarity and emergency preparation questions, which allow respondents to select more than one response, we sum the number of items selected (excluding "none of the above") to create variables measuring degrees of awareness or preparedness. Two responses are included in only some surveys (not all): familiarity with the New Yorker article "The Really Big One" and preparation by purchasing home earthquake insurance. For comparability these are excluded from the sum variable and are treated as separate dummy variables. Each of the response options for who should pay for EEW (federal government, non-profit organizations, etc.) are treated as separate dummy variables.

Although some questions are asked of all respondents, others are included in only some surveys, , generating responses that are missing completely at random (MCAR). In order to run regressions using all available data in models including these variables with partial responses, we impute missing data using the R package "Amelia" (King et al., 2001). Imputations are carried out separately for each round of surveys (e.g., data missing from the three September 2015 surveys are imputed together, but none of the data from the two June 2015 surveys are used in the imputations). The imputed data are used for the models, but are not reported in the summary statistics.

Willingness to pay, which is the dependent variable in our models, is the only continuous variable in the survey. The skewed distribution for WTP, described below, presents problems for its use as a response variable in regression models. To address this, our OLS models use two different transformations. In one specification we trim the top $5 \%$ of responses, which brings the maximum value down from $\$ 100$ to between $\$ 15$ and $\$ 50$, depending on the survey, thereby reducing the influence of a few outliers on the model. We suspect that many of these very high responses do not reflect a genuine WTP and can be safely discarded. In the second specification, we convert WTP to a binary dependent variable split at the median: 0 for all responses less than $\$ 1$, and 1 for all responses of $\$ 1$ or more (with no trimming). We tested various log transformations, but do not report them here as they did not yield a better fit, and were more difficult to interpret.

For each of the two WTP transformations we run three different model specifications. The first includes the earthquake experience variable as an explanatory variable, with "Yes" and "Not sure" as separate dummy variables, and "No" experience as the base case. The second and third specifications take into account that earthquake experience might interact with variables, for example that household preparedness may influence WTP more for those with earthquake experience than those without. These 
models include a dummy variable representing earthquake experience as well as interaction terms (the dummy interacted with each of the other explanatory variables in the model). ${ }^{2}$

Except where otherwise noted, all regression coefficients are standardized.

\section{Results}

\subsection{Summary Statistics}

\subsubsection{Experience}

About two thirds of the WA population has experienced an earthquake (Figure 2), as compared to an estimated 70\% in California and 54\% in Oregon, in the September 2014 survey. In the WA June 2015 survey, only $49 \%$ report having experienced an earthquake $(\mathrm{N}=18,606)$, although this is in response to a check-all-that-apply question. This question format tends to produce underestimates of specific items, as respondents may not read all of the options carefully (Dillman et al 2003; Smyth et al 2006); to avoid order effects we randomly varied the order of presentation of the responses for this question.

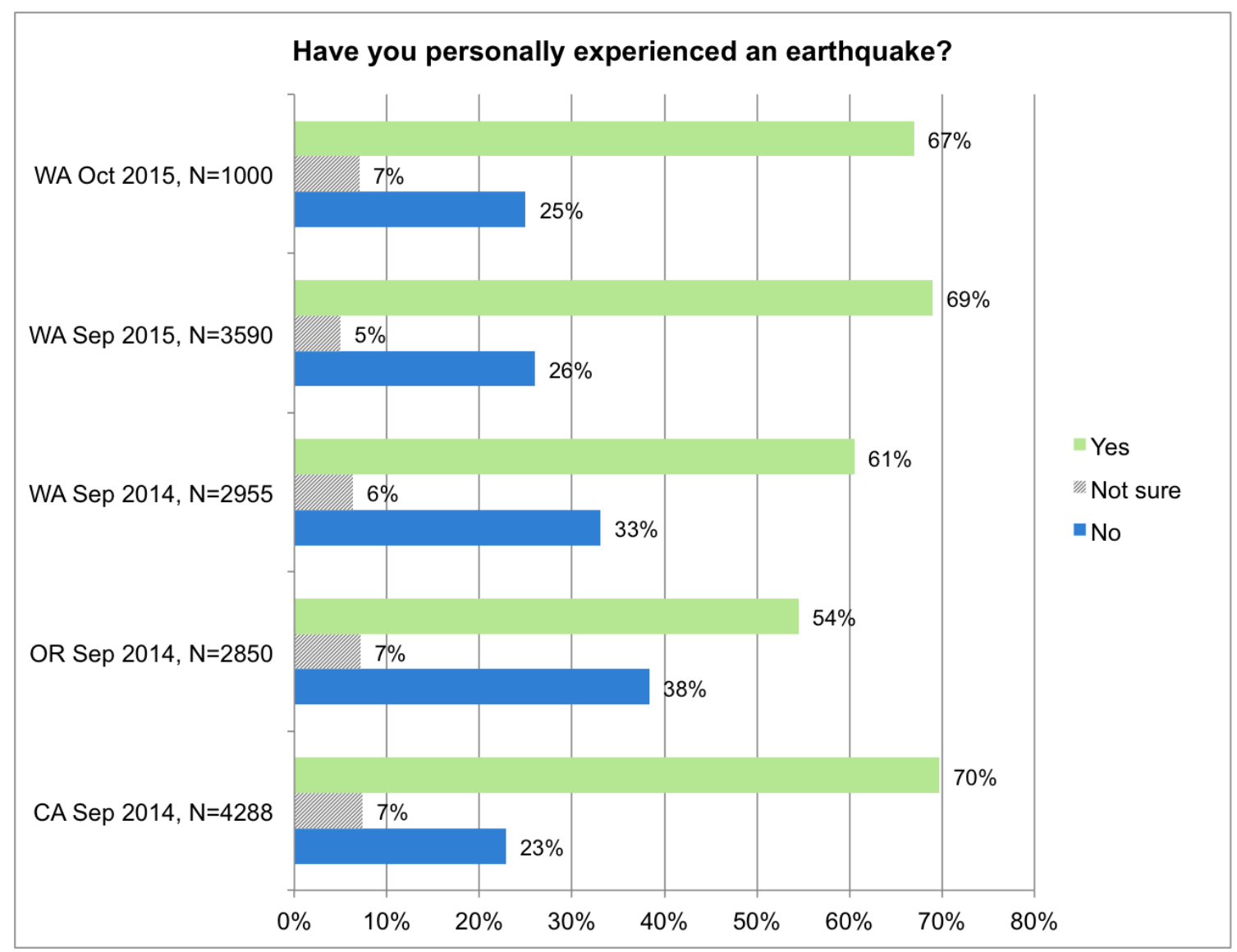

Figure 2. Earthquake Experience on the U.S. West Coast.

${ }^{2}$ To estimate the variance for the interaction coefficients, we run two separate interaction models: one with an interaction term of 1 for earthquake experience, the other with an interaction term of 1 for no or unsure earthquake experience. 


\subsubsection{Response to earthquakes}

Of those who have not experienced an earthquake, a plurality of $35 \%$ say that they would "drop, cover, and hold on" if they experienced an earthquake. However, $51 \%$ of the respondents who report having experienced an earthquake say that they "stopped and stayed put" and only $20 \%$ dropped, covered and held on during their most recent earthquake experience. Since we do not hypothesize any relationship between specific expected or actual responses to earthquakes and perceptions of EEW, responses to this question are not included in the WTP model discussed below.

We also find differences in affective response. Of respondents with earthquake experience, 39\% report very little or no reaction and only $9 \%$ report being "very" or "extremely" frightened. In contrast, of those with no earthquake experience, $26 \%$ say they are very or extremely frightened when they think of being in an earthquake.

\subsubsection{Risk Perception}

Respondents who have experienced an earthquake are more likely to expect an earthquake in the next year. Forty-six percent of respondents with experience say an earthquake is either "likely" or "about as likely as not," compared to just $28 \%$ of those without experience.. However, this comparison does not account for possible geographic differences between these two groups, as those with previous experience might live in locations that are also more exposed to future earthquakes. Perhaps surprisingly, then, the perceived likelihood of being harmed by an earthquake is more comparable between the two groups (Table 1). In both groups, more than half say they are "extremely" or "very" unlikely to be harmed by an earthquake in the next year, and approximately one in six respondents in each group say harm is "likely" or "about as likely as not," which history would suggest is an overestimate.

Table 1. Risk perceptions of earthquakes, including subjective likelihood of experiencing an earthquake in the next year, and of being harmed by an earthquake in the next year.

\section{Have not experienced EQ Have experienced EQ}

\begin{tabular}{lrrrr}
$\begin{array}{l}\text { How likely are you to be harmed by an } \\
\text { earthquake in the next year? }\end{array}$ & Sept. '14 & Sept. '15 & Sept. '14 & Sept. '15 \\
\hline \multicolumn{1}{c}{$\mathrm{N}=$} & 603 & 411 & 601 & 562 \\
\hline $\begin{array}{l}\text { Extremely unlikely (less than 1\% chance) } \\
\text { Very unlikely (less than 10\% chance) }\end{array}$ & $40 \%$ & $37 \%$ & $36 \%$ & $33 \%$ \\
$\begin{array}{l}\text { Unlikely (less than 33\% chance) } \\
\text { About as likely as not (33\% to 66\% }\end{array}$ & $19 \%$ & $20 \%$ & $22 \%$ & $22 \%$ \\
$\quad$ chance) & $21 \%$ & $27 \%$ & $25 \%$ & $26 \%$ \\
Likely (more than 66\% chance) & $10 \%$ & $9 \%$ & $12 \%$ & $15 \%$ \\
\hline
\end{tabular}

\subsubsection{Effectiveness of EEW}

A majority of all respondents say that they would find EEW effective, with about three-quarters agreeing or strongly agreeing that they would be better able to protect themselves from earthquake risks with an early alert (Table 2). Those with experience were only slightly more likely to agree than those without. By comparison, those with experience have much higher levels of agreement with the statement that "earthquake hazard mitigation, such as reinforcing buildings, reduces the risk of death from 
earthquakes" (Table 2). Only $7 \%$ of respondents with experience disagree, versus $21 \%$ of those who have not experienced an earthquake.

Table 2. Perceived effectiveness of earthquake early warning and hazard mitigation as protective actions (also referred to as "response efficacy").

Have not experienced EQ $\quad$ Have experienced EQ

I would be better able to

protect myself from

earthquake risks, including

death, with an earthquake

early alert.

June June

\begin{tabular}{|c|c|c|c|c|c|c|c|}
\hline early alert. & & ot. '14 & '15 & Sept. '15 & Sept. '14 & '15 & Sept. '15 \\
\hline & $\mathrm{N}=$ & 597 & 84 & 410 & 600 & 332 & 558 \\
\hline Strongly Disagree & & $11 \%$ & $11 \%$ & $11 \%$ & $5 \%$ & $7 \%$ & $8 \%$ \\
\hline Disagree & & $15 \%$ & $15 \%$ & $16 \%$ & $13 \%$ & $11 \%$ & $16 \%$ \\
\hline Agree & & $46 \%$ & $32 \%$ & $49 \%$ & $52 \%$ & $47 \%$ & $49 \%$ \\
\hline Strongly Agree & & $28 \%$ & $42 \%$ & $24 \%$ & $30 \%$ & $35 \%$ & $28 \%$ \\
\hline
\end{tabular}

Have not experienced EQ $\quad$ Have experienced EQ

Earthquake hazard

mitigation, such as

reinforcing buildings,

reduces the risk of death

from earthquakes

\begin{tabular}{|c|c|c|c|c|c|c|c|}
\hline & $\mathrm{N}=$ & 597 & 85 & 408 & 297 & 328 & 307 \\
\hline Strongly Disagree & & $11 \%$ & $12 \%$ & $9 \%$ & $3 \%$ & $5 \%$ & $3 \%$ \\
\hline Disagree & & $10 \%$ & $11 \%$ & $12 \%$ & $2 \%$ & $5 \%$ & $3 \%$ \\
\hline Agree & & $49 \%$ & $46 \%$ & $48 \%$ & $42 \%$ & $46 \%$ & $47 \%$ \\
\hline Strongly Agree & & $30 \%$ & $32 \%$ & $32 \%$ & $53 \%$ & $44 \%$ & $47 \%$ \\
\hline
\end{tabular}

\subsubsection{Familiarity}

Respondents have a higher level of familiarity with earthquake early warning than expected (Table 3). $35 \%$ of those without experience and $60 \%$ of those with experience say they have heard of EEW. By comparison, aftershocks were the most familiar topic of the list provided, with about half of respondents without experience and three-quarters of those with experience saying they have heard of them. For all topics, respondents with earthquake experience have greater familiarity than those without.

Table 3. Familiarity with earthquake topics.

\begin{tabular}{|c|c|c|c|c|c|c|}
\hline \multirow[b]{2}{*}{$\begin{array}{l}\text { Which of the following earthquake- } \\
\text { related topics have you heard of? }\end{array}$} & \multicolumn{3}{|c|}{ Have not experienced EQ } & \multicolumn{3}{|c|}{ Have experienced EQ } \\
\hline & $\begin{array}{r}\text { Sept. } \\
114 \\
\end{array}$ & $\begin{array}{r}\text { June } \\
\text { '15 } \\
\end{array}$ & $\begin{array}{r}\text { Sept. } \\
115\end{array}$ & $\begin{array}{r}\text { Sept. } \\
114 \\
\end{array}$ & $\begin{array}{r}\text { June } \\
\text { '15 } \\
\end{array}$ & $\begin{array}{r}\text { Sept. } \\
1 \\
\end{array}$ \\
\hline $\mathrm{N}=$ & 603 & 86 & 411 & 601 & 332 & 562 \\
\hline
\end{tabular}




\begin{tabular}{lrrrrrr} 
Earthquake aftershocks & $49 \%$ & $56 \%$ & $44 \%$ & $82 \%$ & $79 \%$ & $64 \%$ \\
Earthquake early warnings or alerts & $32 \%$ & $44 \%$ & $37 \%$ & $62 \%$ & $68 \%$ & $52 \%$ \\
Cascadia Subduction Zone & $19 \%$ & $21 \%$ & $28 \%$ & $36 \%$ & $42 \%$ & $49 \%$ \\
Manmade earthquakes & $18 \%$ & $26 \%$ & $20 \%$ & $31 \%$ & $39 \%$ & $31 \%$ \\
Earthquake Swarms & $11 \%$ & $22 \%$ & $12 \%$ & $26 \%$ & $32 \%$ & $21 \%$ \\
New Yorker article "The Really Big & - & - & $28 \%$ & - & - & $40 \%$ \\
One" & - & $-14 \%$ & $22 \%$ & $10 \%$ & $6 \%$ & $13 \%$ \\
None of the above & $28 \%$ & $14 \%$ \\
\hline
\end{tabular}

\subsubsection{Preparations}

Respondents who have experienced earthquakes are also more likely to have made emergency preparations in their home. Sixty-five percent have a first aid kit and 55\% have a supply of food and water, compared to $38 \%$ and $30 \%$ in the group without experience. Similarly, those with earthquake experience are more likely to have an emergency plan, to have identified a safe zone, and to hold earthquake insurance (see Appendix). Eighteen percent of those with earthquake experience and $31 \%$ of those without say they have none of the listed preparations.

\subsubsection{Willingness to Pay}

The distribution of WTP has a strong positive skew. Mean responses hover around \$6, ranging between about $\$ 3$ and $\$ 12$ (Table 4), and each survey has at least one response of $\$ 100$, the maximum allowed. The median response is $\$ 1$ in all waves except September 2015, and between a third and half of respondents answer $\$ 0$. Respondents without earthquake experience tend to report a higher WTP than those with experience, although the percent answering $\$ 0$ is comparable in each group.

Table 4. Willingness to pay per month for an earthquake early alert application (smart phone or computer).

\begin{tabular}{|c|c|c|c|c|c|c|c|c|}
\hline $\begin{array}{l}\text { EQ } \\
\text { Experience }\end{array}$ & Survey & State & $\mathrm{N}=$ & Mean & $\begin{array}{l}\text { Percent } \\
\$ 0\end{array}$ & Median & $\begin{array}{l}75 \text { th } \\
\text { percentile }\end{array}$ & $\begin{array}{l}\text { 95th } \\
\text { percentile }\end{array}$ \\
\hline \multirow[t]{5}{*}{ No/Not sure } & Sep '14 & $\mathrm{CA}$ & 200 & $\$ 8.88$ & $42 \%$ & $\$ 1$ & $\$ 9.25$ & $\$ 50.25$ \\
\hline & & OR & 202 & 6.01 & 38 & 1 & 5.00 & 24.95 \\
\hline & & WA & 201 & 6.23 & 39 & 1 & 5.00 & 30.00 \\
\hline & Jun '15 & WA & 86 & 12.45 & 24 & 1 & 5.00 & 85.50 \\
\hline & Sep '15 & WA & 411 & 6.62 & 50 & 0 & 2.00 & 52.40 \\
\hline \multirow[t]{5}{*}{ Yes } & Sep '14 & $\mathrm{CA}$ & 200 & 5.39 & 30 & 1 & 5.00 & 12.15 \\
\hline & & OR & 200 & 6.62 & 36 & 1 & 5.00 & 50.00 \\
\hline & & WA & 201 & 5.32 & 40 & 1 & 5.00 & 20.00 \\
\hline & Jun '15 & WA & 332 & 6.88 & 43 & 1 & 5.00 & 50.00 \\
\hline & Sep '15 & WA & 562 & 3.42 & 55 & 0 & 2.00 & 10.00 \\
\hline
\end{tabular}




\subsection{Model Results}

Fig. 3 Coefficient plot of median split models, including interactions of all variables with earthquake experience. Shown in orange are the coefficients and $95 \%$ confidence intervals for those without (or unsure of) earthquake experience. In blue are the coefficients and 95\% confidence intervals for those with earthquake experience.

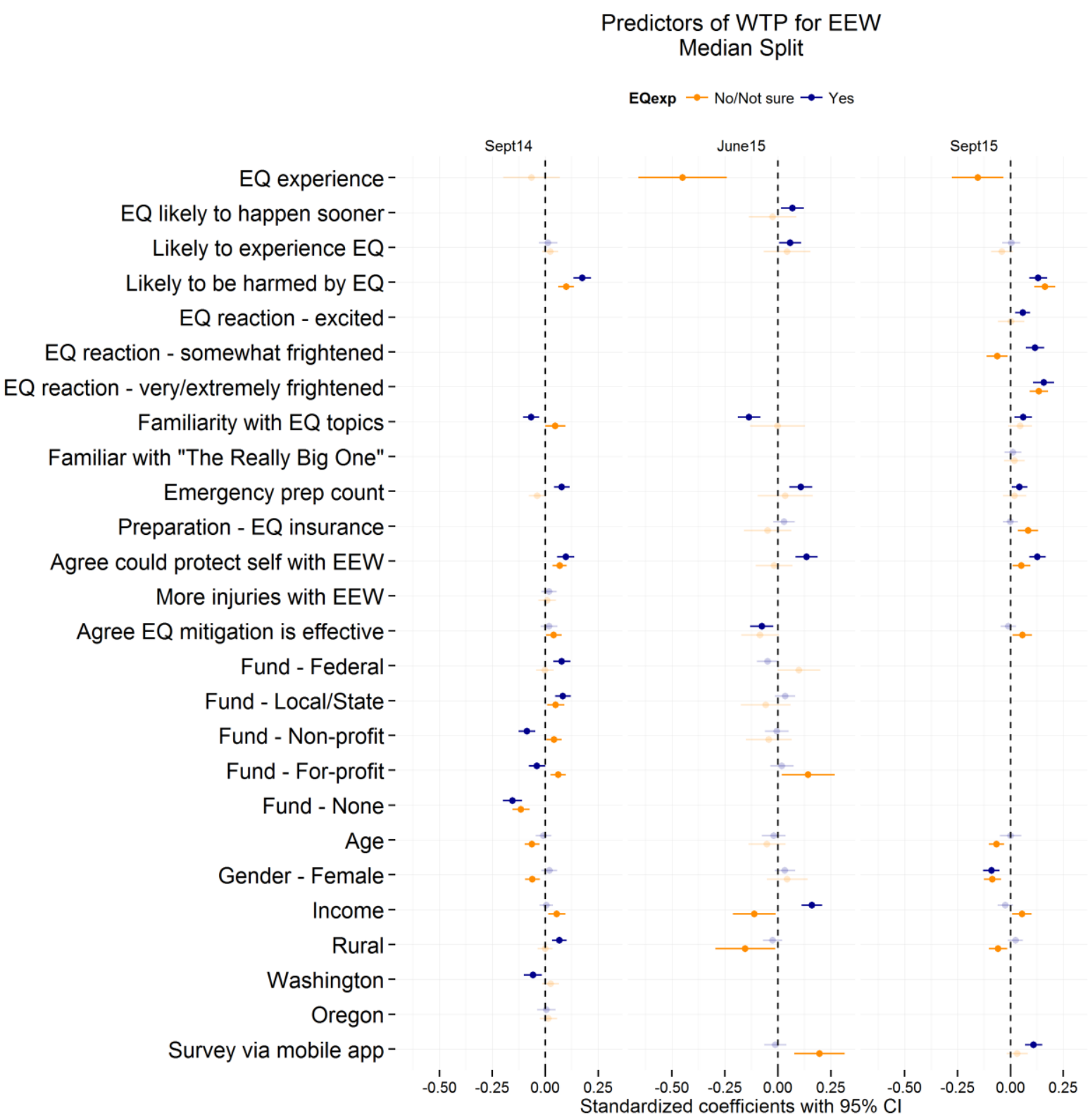


Fig. 4. Coefficient plot of $95 \%$ trimmed OLS models, including interactions of all variables with earthquake experience. Shown in orange are the coefficients and $95 \%$ confidence intervals for those without (or unsure of) earthquake experience. In blue are the coefficients and $95 \%$ confidence intervals for those with earthquake experience.

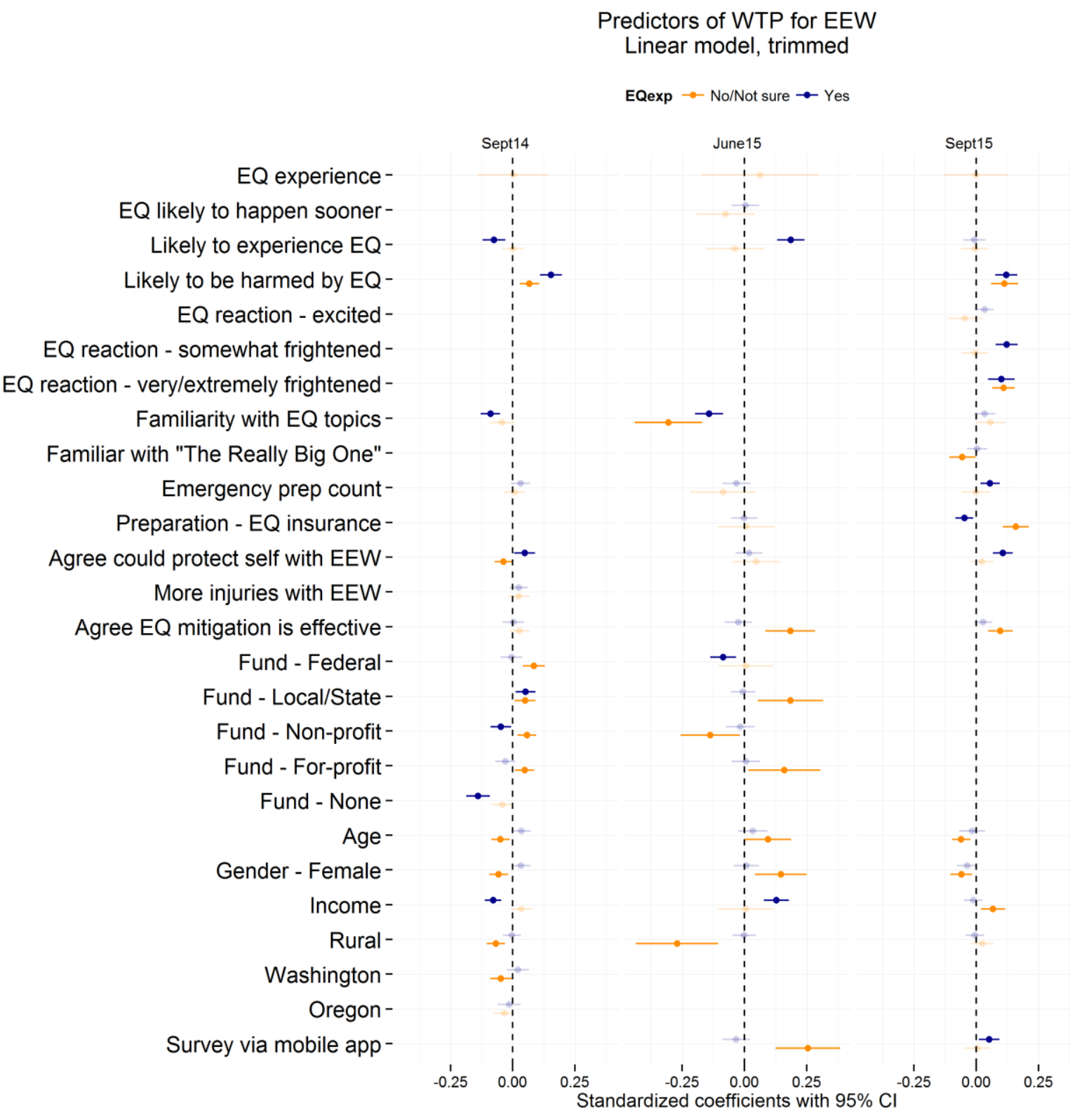


Examining the estimated coefficients across all models (Figures 3 and 4), those variables that are robustly associated with WTP for EEW as expected include the subjective likelihood of being harmed by an earthquake (perceived threat), experienced or predicted extreme fright (emotional / affective response), belief that one can protect oneself with earthquake early warning (efficacy), and vicarious experience of an earthquake. We discuss each in turn.

Subjective likelihood of being harmed by an earthquake (positive coefficient): As expected, a respondent who thinks it is more likely that they will be harmed by an earthquake, will have a higher WTP, all else held constant. In a related analysis, we coded expectations of more injuries with EEW as a separate variable, to check if people thought EEW might lead to poor action choices. These estimated coefficients are insignificant across all models, suggesting that there is not much concern for this possible side effect of EEW.

Subjective likelihood of experiencing a hazard has been measured in many studies (e.g., Bourque et al., 2012; see also Lindell and Perry 2000). Expected exposure to an earthquake is one aspect of vulnerability that is often discussed by experts and in the press. We find that if we control for expectations of being harmed (as we do in the September models), there is either no association, or the higher the perceived likelihood, the higher the WTP (this is measured in two ways, as being likely to experience an earthquake, and as expecting an earthquake sooner). Once we control for perceived likelihood of being harmed, this subjective judgment becomes insignificant in the models.

Experienced or predicted extreme fright (positive coefficient): As expected, anticipated or experienced fear (very or extremely frightened in response to an earthquake) is associated with a higher WTP; this association does not vary by earthquake experience. While being somewhat frightened in response to an experienced earthquake is associated with higher stated WTP, anticipating being only "somewhat frightened" is associated with a slightly lower WTP, all else equal. Those who experienced excitement in response to an earthquake experience express higher WTP, whereas the anticipation of excitement does not appear to influence WTP in the absence of earthquake experience.

Agree can protect self with EEW (positive coefficient): A perception of higher efficacy with EEW is, overall, associated with higher WTP. However, in a single model (95\% trimmed model Sep 2014, see Figure $\mathrm{X}$ ), those without earthquake experience or unsure of whether they had experienced an earthquake were (inexplicably) willing to pay less the higher the perceived EEW efficacy.

Vicarious experience (positive coefficient): Having recently seen the movie "San Andreas" is associated with a higher WTP, all else equal. Because this was assessed only in the June 2015 surveys, we do not include this in Figures $\mathrm{X}$ and $\mathrm{Y}$.

Less robust influences on WTP that are still generally in the expected direction include those of emergency preparations, beliefs in the efficacy of structural risk mitigation, awareness of earthquake topics, and income.

Emergency preparations / insurance (positive coefficient): We expected those who had prepared more to be more interested in EEW, and so state a higher WTP. Overall, there is a suggestion that this holds, though the coefficients are very small, and negative in some models for those who have not experienced an earthquake. Those who have earthquake insurance are overall, if anything, willing to pay slightly more for EEW, but this varies by earthquake experience; the tendency toward higher WTP is driven by those without earthquake experience. 
Agree structural earthquake risk mitigation is effective (positive coefficient): Overall, the results suggest that there is not a perceived tradeoff between structural mitigation and interest in EEW, as those who agree earthquake mitigation is effective are if anything willing to pay more for EEW.

Awareness of earthquake topics (positive coefficient after controlling for emotional response) / The Really Big One: In the Sep 2015 model we controlled for emotional response, and in that model, the coefficient on familiarity with earthquake topics is in the expected direction: the greater the number of topics with which the respondent is familiar, the higher the WTP, though the coefficients are very small. In the Sep 2014 and June 2015 models we did not control for emotional response to earthquakes. In those models, the coefficient on familiarity is negative: the greater the number of earthquake topics with which the respondent is familiar, the lower the stated WTP. Despite the high penetration of the New Yorker article, it does not appear directly influence WTP for EEW once we control for other factors (such as the anticipated emotional response to an earthquake).

Income (positive coefficient): In most of the models without earthquake interactions, the coefficient on income is positive, as we would expect, though not always significant. When we add interactions with earthquake experience, this positive association is reduced or eliminated for those with earthquake experience. Krupnick et al. (2002) find that those in the bottom $25 \%$ of income are willing to pay less than others. In a sensitivity analyses we applied this same split on income and found it did not alter the modeling results meaningfully.

Geography: Respondents without earthquake experience in rural areas express lower WTP than those in urban or suburban area. Controlling for other factors, we see no differences between reactions in $\mathrm{OR}$ and CA. If we look at WA state level responses by earthquake experience, how WA responses compare to those in CA depends on the model (unstable). Overall there are no significant differences, all else equal.

Funding the system: As one would expect, those who answer that "none of the above" should fund an EEW system give a lower WTP. Those who think the federal government should fund EEW express slightly higher WTP, in general, though this finding varies a little by model. Those who think local or state government should fund EEW express higher WTP, though not significantly more if they have had earthquake experience, in the June model. Those who think for-profit entities should fund EEW and have not had earthquake experience are willing to pay more, whereas two of the models suggest that this WTP increase disappears if they have had earthquake experience. Overall, the results suggest that thinking the overall system should be funded by government or others does not reduce WTP for an EEW app.

Four unexpected findings are more difficult to explain, including the estimated coefficients for having experienced an earthquake, for age, for gender, and for having taken the survey on a mobile.

Has experienced an earthquake (negative/variable coefficient): The mixed findings (with negative coefficients in half of the models) for the earthquake experience dummy suggest that earthquake experience has its effect through other variables, including expectations of harm, and expectations of being able to protect oneself effectively with EEW. Those who are not sure if they have experienced an earthquake express a slightly higher WTP than those who have not experienced an earthquake, overall; this is a very small proportion of the sample.

Age (negative/mixed coefficient): An unexpected association with age appears in the June survey, in which experience was measured with a select-all-that-apply question. The coefficient on age is positive for the June survey, with no significant interaction with earthquake experience. In all other waves, all else equal, those who are older give a lower WTP (in five out of six models), although the 
interaction with earthquake experience suggests that this is mitigated some by earthquake experience.

Female (negative/mixed coefficient): We expected that all else equal, women would be willing to pay more for EEW than men (e.g., as found in Krupnick et al 2002), but we do not see this. Our findings are mixed, both with regard to the significance and direction of the association.

Took survey on a mobile (positive coefficient): Though we initially expected no differences between those who took the survey on a mobile and other, concerns about response biases stemming from how the survey was administered led us to control for whether respondents used Google's mobile survey app, through which Android users complete surveys in exchange for Google Play credit. We found overall a slight tendency to report a higher WTP via this app, though this appears to be mitigated some by earthquake experience, all else equal.

\section{Discussion and Conclusions}

A complete view of hazard forecast and warning systems includes behavioral responses and recognizes that short-term warnings require long-term social and organizational preparation and integration in order to be effective (e.g., NRC 2010). A key lesson from prior research on hazard warnings is that people need actionable information on what to do, not just awareness of the existence of a threat (Wood et al. 2012). Public concerns about the efficacy of evacuation procedures and about warning times have been identified as pervasive in surveys of Washington coastal communities (e.g., Houghton et al. 2009). In addition, the typically short time between the detection and arrival of shaking in EEW poses technological challenges that most current alert systems cannot meet, although the Warning, Alert, and Response Network (WARN) Act of 2006 establishes a national all-hazards alert system that includes wireless telecommunications, e.g., cellphones, for imminent threat alerts (NRC 2013). Despite these challenges, ShakeAlert and the development of EEW for the U.S. West Coast provides a very large net potential benefit (Bouta, 2015; Calkins and Lieberman 2015; Strauss and Allen, 2016).

Findings from the surveys reported here are largely cause for optimism with regard to receptivity and interest in earthquake early warning on the U.S. West Coast. Respondents are generally aware of seismic risks, with many overestimating their short-term vulnerability, although the number who have made appropriate household emergency preparations is smaller than hazard planners might hope. A much higher percentage of the public had heard of EEW than expected, and a majority were interested in EEW. We find general agreement that seconds to minutes of warning would help individuals to take protective action and would be effective in reducing seismic risk. Rather than seeing EEW as trading off against structural mitigation to protect against earthquakes, those who perceive structural mitigation as effective are more likely to be interested in EEW and see it as likely to be an effective protective response measure. A majority of the surveyed population said they are willing to personally invest at least something for EEW.

Several findings and implications for communication also emerge. First, we find evidence that mass media communications help raise awareness of seismic hazards and increase support for risk mitigation. The Pulitzer prize-winning article "The Really Big One" reached over a fourth of those without earthquake experience, and $40 \%$ of those with earthquake experience. The higher penetration for those with earthquake experience is to be expected from recent research on selective attention and "reinforcing" spirals of exposure to information, experience, and attitude formation (Feldman et al., 2014; Slater 2015; Zhao 2009; see also Karlsson et al 2009). "The Really Big One" appears to have reinforced thinking about earthquake risks in the PNW, increasing expectations of an (earlier) big earthquake. Further, seeing the movie San Andreas was associated with an increase in WTP. However, in the weeks 
following its release only a small proportion (less than 3\%) of the Washington state public saw the film "San Andreas." The systematic differences between anticipated and reported responses to earthquakes point to the ongoing need for communication and education about what to do in the event of an earthquake, which must address the potential for earthquakes much greater than those experienced on the West Coast in recent years.

Second, our findings underscore the importance of considering the content of warning messages to promote effective protective action. Only one in five of respondents who have experienced an earthquake said that they dropped and covered when they felt shaking, although a third of those without experience said that they would do so. An early warning message with clear directions could help people to anticipate shaking and take appropriate action.

Finally, we find evidence supporting our expectation that those who perceive EEW to be effective at helping them to protect themselves are more likely to support it. This suggests that the case for public investment in EEW can be made stronger if people believe in the risk mitigating potential of the system. Although familiarity with EEW was somewhat higher than expected, perhaps half of the overall West Coast population still does not know about it. As awareness of EEW spreads, there is a need for accompanying information about its potential effectiveness together with more general seismic risk reduction education. Such a campaign must be honest about the limitations of EEW, including the potential for false positives, in order to set appropriate expectations. Further research should examine the extent to which potential users understand EEW, including the potential for missed and false warnings.

Several methodological issues must be raised as potential caveats to the findings, including the known problems exhibited by WTP estimation, which is a problematic measure of support for EEW, and the potential bias introduced by mobile survey app use. Nevertheless, although the models explain in general less than $10 \%$ of the variance in WTP, the modeling and survey approach are promising in several regards. Assuming providers (like Google) continue to invest in the development and transparency of its survey tools, such paywall intercept surveys provide a potentially affordable and defensible path to assessing public attitudes and beliefs on hazards and resilience, in a time when other survey approaches are becoming increasingly expensive and facing ever dwindling response rates.

This study illustrates one way in which internet and communication technologies are enabling much more rapid involvement of publics at a massive scale. Another is the development of social media data collection strategies for post-earthquake damage assessment and information provision (Bossu et al., 2015), which appear to be increasing in importance. Combining the type of survey research strategy proposed here with such strategies is a promising next step; an integrated pre- and post-event data collection and analysis strategy of this sort could enable scientists to better understanding people's expectations and experiences, and ultimately better prepare them for hazards.

\section{References}

Allen, R. (2001). Seconds before the big one. Scientific American, April, 2001, pp 74-79.

Allen, R. M. (2011). Earthquakes, early and strong motion warning. In Encyclopedia of Solid Earth Geophysics, Springer Netherlands. pp. 226-233.

Becker, J. S., Johnston, D. M., Paton, D., \& Ronan, K. (2012a). How people use earthquake information and its influence on household preparedness in New Zealand. Journal of Civil Engineering and Architecture, 6(6), 673. 
Becker, J. S., Paton, D., Johnston, D. M., \& Ronan, K. R. (2012b). A model of household preparedness for earthquakes: how individuals make meaning of earthquake information and how this influences preparedness. Natural hazards, 64(1), 107-137.

Bossu, R., Laurin, M., Mazet-Roux, G., Roussel, F., \& Steed, R. (2015). The Importance of Smartphones as Public Earthquake-Information Tools and Tools for the Rapid Engagement with Eyewitnesses: A Case Study of the 2015 Nepal Earthquake Sequence. Seismological Research Letters, 86(6), 1587-1592.Bostrom, A., Morss, R.E., Lazo, J.K., Demuth, J.L., Lazrus, H. and Hudson, R. (2016). A mental models study of hurricane forecast and warning production, communication, and decision making, Weather Climate and Society, 8(2): 111-129.

Bourque, L. B., Regan, R., Kelley, M. M., Wood, M. M., Kano, M., \& Mileti, D. S. (2012). "An examination of the effect of perceived risk on preparedness behavior." Environment and Behavior, 45(5), 615-649.

Bouta, A. (2015). A Benefit-Cost Analysis for the Proposed Pacific Northwest Earthquake Early Warning System. Masters Capstone Report, Daniel J. Evans School of Public Policy and Governance, University of Washington, Seattle, WA.

Calkins, A. and Lieberman, E. (2015). "The Benefits and Costs of an Earthquake Early Warning System in Washington State.” Evans School Review, Daniel J. Evans School of Public Policy and Governance, University of Washington, 2015. Accessed June 2016 at https://depts.washington.edu/esreview/esr-journal-2015/

Demuth, J.L. (2015). Developing a Valid Scale of Past Tornado Experiences. Dissertation in Technology and Communications, Colorado State University.

Dillman, D. A., Smyth, J. D., Christian, L. M., \& Stern, M. J. (2003). Multiple-answer questions in selfadministered surveys: The use of check-all-that-apply and forced-choice question formats. In meetings of the American Statistical Association, San Francisco, CA.

Eiser, R.J., A. Bostrom, I. Burton, D.M. Johnston, J. McClure, D. Paton, J. van der Pligt, M.P. White (2012). Risk interpretation and action: A conceptual framework for responses to natural hazards. International Journal of Disaster Risk Reduction, http://dx.doi.org/10.1016/j.ijdrr.2012.05.002.

Feldman, L., Myers, T. A., Hmielowski, J. D., \& Leiserowitz, A. (2014). The mutual reinforcement of media selectivity and effects: Testing the reinforcing spirals framework in the context of global warming. Journal of Communication, 64(4), 590-611.

Finucane, M. L., Alhakami, A., Slovic, P., \& Johnson, S. M. (2000). The affect heuristic in judgments of risks and benefits. Journal of Behavioral Decision Making, 13, 1-17.

Fujinawa, Y., \& Noda, Y. (2013). Japan's earthquake early warning system on 11 March 2011: performance, shortcomings, and changes. Earthquake Spectra, 29(s1), S341-S368.

Given, D.D., Cochran, E.S., Heaton, T., Hauksson, E., Allen, R., Hellweg, P., Vidale, J., and Bodin, P., (2014), Technical implementation plan for the ShakeAlert production system-An Earthquake Early Warning system for the West Coast of the United States: U.S. Geological Survey Open-File Report 2014-1097, 25 p., http://dx.doi.org/10.3133/ofr20141097.

Goltz, J.D. (2002). "Introducing Earthquake Early Warning in California: A Summary of Social Science and Public Policy Issues." Caltech Seismological Laboratory, Disaster Assistance Division, A report to OES and the Operational Areas.

Goltz J.D. (2003). Applications for New Real-time Seismic Information: The TriNet Project in Southern California. Seismological Research Letters. 74(5) 516-521.

Goltz, J. D., \& Mileti, D. S. (2011). Public response to a catastrophic Southern California earthquake: a sociological perspective. Earthquake Spectra, 27(2), 487-504.

Heki, K. (2011). A Tale of Two Earthquakes..Science, 332, 1390-1391.

Hoshiba, M. (2014) "Review of the Nationwide Earthquake Early Warning in Japan during Its First Five Years." Chapter in Earthquake Hazard, Risk, and Disasters. Waltham, MA: Elsevier/Academic Press. Pages 505-529. 
Hoshiba, M., Iwakiri, K., Hayashimoto, N., Shimoyaya, T., Hirano, K., Yamada, Y., Ishigaki, Y., et al. (2011). Outline of the 2011 off the Pacific coast of Tohoku Earthquake (Mw 9.0): Earthquake Early Warning and observed seismic intensity. Earth, Planets and Space, 63, 547-551.

Hough, S., and Jones, L. (2002) “Earthquakes don't kill people, buildings do”. San Francisco Chronicle, December 4.

Houghton, B. F.; Gregg, C. E.; Larin, P. N.; Johnston, D. M.; Paton, D.; Gill, D. A.; Ritchie, L. A., 2009, Public attitudes and perceptions of tsunamis and warning systems in Oregon and Washington-The case study of Ocean Shores and Seaside [abstract]:Geological Society of America Abstracts with Programs, v. 41, no. 7, p. 521.

Johnston, D. M.; Paton, Douglas; Houghton, B. F.; Becker, J.; Crumbie, G., 2002, Results of the AugustSeptember 2001 Washington State tsunami survey: Institute of Geological and Nuclear Sciences LimitedScience Report 2002/17, 53 p.

Johnston, D.; Paton, D.; Crawford, G. L.; Ronan, K.; Houghton, B.; Burgelt, P., 2005, Measuring tsunami preparedness in coastal Washington, United States. IN Bernard, E. N., editor, Developing tsunami-resilient communities--The National Tsunami Hazard Mitigation Program: Springer, p. 173-184.

Johnston, D.M.; Becker, J.S.; Gregg, C.; Houghton, B.F.; Paton, D.; Leonard, G.S.: Garside, R. (2007) Developing warning and disaster response capacity in the tourism sector in coastal Washington, USA. Disaster prevention and management, 16(2): 210-216

Johnston, D., Standring, S., Ronan, K., Lindell, M., Wilson, T., Cousins, J., Aldridge, E., Ardagh, M. W., Deely, J. M., Jensen, S. (2014). The 2010/2011 Canterbury earthquakes: context and cause of injury. Natural Hazards, 73(2), 627-637.

Jones-Lee, M., Hammerton, M., and Philips, P. (1985). "The Value of Safety: Results of a National Sample Survey". Economic Journal 95, 49-72.

Karlsson, N., Loewenstein, G., \& Seppi, D. (2009). The ostrich effect: Selective attention to information. Journal of Risk and uncertainty, 38(2), 95-115.

Keller, C., Siegrist, M., \& Gutscher, H. (2006). The role of the affect and availability heuristics in risk communication. Risk analysis, 26(3), 631-639.

King, G. Honaker, J., Joseph A., Scheve K. (2001). Analyzing Incomplete Political Science Data: An Alternative Algorithm for Multiple Imputation. American Political Science Review 95(1), 49-69.

Krupnick, A., Alberini, A., Cropper, M. et al. (2002). Age, health and the willingness to pay for mortality risk reductions: A contingent valuation survey of Ontario residents. Journal of Risk and Uncertainty 24(2), 161-186. doi:10.1023/A:1014020027011

Lazo, J. K., Bostrom, A., Morss, R. E., Demuth, J. L. and Lazrus, H. (2015), Factors Affecting Hurricane Evacuation Intentions. Risk Analysis, 35: 1837-1857. doi: 10.1111/risa.12407

Leonard, G. S., Johnston, D. M., Paton, D., Christianson, A., Becker, J., Keys, H. (2008). Developing effective warning systems: On-going research at Ruapehu volcano, New Zealand. Journal of Volcanology and Geothermal Research, 172(3-4), 199-215. doi: 10.1016/j.jvolgeores.2007.12.008

Lindell, M.K. \& Perry, R.W. (2012). The Protective Action Decision Model: Theoretical modifications and additional evidence. Risk Analysis, 32, 616-632.

Lindell, M.K. \& Perry, R.W. (2000). Household adjustment to earthquake hazard: A review of research. Environment and Behavior, 32, 461-501.

Lindell, M.K., Arlikatti, S. \& Prater, C.S. (2009). Why people do what they do to protect against earthquake risk: Perceptions of hazard adjustment attributes. Risk Analysis, 29, 1072-1088.

Lindell, M.K., Prater, C.S., Gregg, C.E., *Apatu, E., *Huang, S-K. \& *Wu, H-C. (2015). Households' immediate responses to the 2009 Samoa earthquake and tsunami. International Journal of Disaster Risk Reduction, 12, 328-340.

Lindell, M.K., Prater, C.S., *Wu, H-C., *Huang, S-K., Johnston, D.M., Becker, J.S. \& Shiroshita, H. (2016). Immediate behavioral responses to earthquakes in Christchurch New Zealand and Hitachi Japan. Disasters,40(1), 85-111. 
Maloney, E. K., Lapinski, M. K., \& Witte, K. (2011). Fear appeals and persuasion: A review and update of the extended parallel process model. Social and Personality Psychology Compass, 5(4), 206219.

McDonald P, Mohebbi M, and Slatkin B. (2015). Comparing the Accuracy of Google Consumer Surveys to Existing Probability and Non-Probability Based Internet and Telephone Surveys. Whitepaper, Google Inc. Originally accessed June 2012, updated version accessed July 2016 at http://www.google.com/insights/consumersurveys/static/consumer_surveys_whitepaper_v2_upda ted.pdf

Mileti, D.S. and J.S. Sorenson. (1990). "Communication of Emergency Public Warnings: A Social Science Perspective and State-of-the-Art Assessment." Oak Ridge, Tennessee: Oak Ridge National Laboratory.

Morgan, M. G., Fischhoff, B., Bostrom, A., \& Atman, C. J. (2002). Risk communication: A mental models approach. Cambridge University Press.

Morss, R. E., Demuth, J. L., Bostrom, A., Lazo, J. K. and Lazrus, H. (2015), Flash Flood Risks and Warning Decisions: A Mental Models Study of Forecasters, Public Officials, and Media Broadcasters in Boulder, Colorado. Risk Analysis, 35: 2009-2028. doi: 10.1111/risa. 12403

National Research Council (NRC), Committee on Public Response to Alerts and Warnings on Mobile Devices: Current Knowledge and Research Gaps (2011). Public Response to Alerts and Warnings on Mobile Devices: Summary of a Workshop on current Knowledge and Research Gaps. National Academies Press, Washington DC, www.nap.edu

National Research Council, Committee on Public Response to Alerts and Warnings Using Social Media: Current Knowledge and Research Gaps, Computer Science and Telecommunications Board, Division on Engineering and Physical Sciences (2013). Public Response to Alerts and Warnings Using Social Media: Report of a Workshop on Current Knowledge and Research Gaps. National Academies Press, Washington DC, www.nap.edu

National Research Council, Committee on the Review of the Tsunami Warning and Forecast System and Overview of the Nation's Tsunami Preparedness, Ocean Studies Board, Earth and Life Studies (2010). Tsunami Warning and Preparedness: An Assessment of the U.S. Tsunami Program and the Nation's Preparedness Efforts. National Academies Press, Washington, D.C..

Paton, D., Anderson, E., Becker, J., \& Petersen, J. (2015). Developing a comprehensive model of hazard preparedness: Lessons from the Christchurch earthquake. International Journal of Disaster Risk Reduction, 14 (1) 37-45.

Riopelle, D., Shoaf, K., Bourque, L. (2001). TriNet Policy Studies and Planning Activities In Real-Time Earthquake Early Warning: Task 1 Report, Survey of Potential Early Warning System Users. UCLA CPDHR, 10911 Weyburn Ave, 2nd floor Los Angeles, CA 90024, http://www.ph.ucla.edu/cphdr

Savage, L. (1993). An empirical investigation into the effect of psychological perceptions on the willingness-to-pay to reduce risk. Journal of risk and uncertainty, 6(1), 75-90.

Slater, M.D. (2015) Reinforcing Spirals Model: Conceptualizing the Relationship Between Media Content Exposure and the Development and Maintenance of Attitudes. Media Psychology, 18:3, 370-395, DOI: 10.1080/15213269.2014.897236

Slovic, P., Finucane, M. L., Peters, E., \& MacGregor, D. G. (2004). Risk as analysis and risk as feelings: Some thoughts about affect, reason, risk, and rationality. Risk Analysis, 24(2), 311-322.

Smyth, J. D., Dillman, D. A., Christian, L. M., \& Stern, M. J. (2006). Comparing check-all and forcedchoice question formats in web surveys. Public Opinion Quarterly, 70(1), 66-77.

Spence R, So E (2009) Estimating shaking-induced casualties and building damage for global earthquake events. NEHRP Technical Report 08HQGR0102. (Assessed on July 18, 2016 from http://earthquake.usgs.gov/research/external/reports/08HQGR0102.pdf)

Strauss, J.A. and Allen, R.M. (2016). Benefits and Costs of Earthquake Early Warning. Seismological Research Letters 87 (3), 765-772. 
Tannenbaum, M. B., Hepler, J., Zimmerman, R. S., Saul, L., Jacobs, S., Wilson, K., \& Albarracín, D. (2015). Appealing to Fear: A Meta-Analysis of Fear Appeal Effectiveness and Theories A Message-Behavior-Audience Framework. Psychiatric Bulletin, 141(6), 1178-1204. http://doi.org/10.1037/a0039729

Tierney, K. (2014). The social roots of risk: Producing disasters, promoting resilience. Stanford University Press.

UNISDR (2015). Making Development Sustainable: The Future of Disaster Risk Management. Global Assessment Report on Disaster Risk Reduction. Geneva, Switzerland: United Nations Office for Disaster Risk Reduction (UNISDR). Accessed May 2016 at http://www.preventionweb.net/english/hyogo/gar/2015/en/home/download.html .

Wenzel, F., Baur, M., Fiedrich, F., Ionescu, C., Ionescu, M.C. (2001). Potential of Earthquake Early Warning Systems. Natural Hazards, 23(2-3), 407-416.

Witte, K. (1992). Putting the fear back into fear appeals: The extended parallel process model. Communications Monographs, 59(4), 329-349.

Wood, M. M., Mileti, D. S., Kano, M., Kelley, M. M., Regan, R., \& Bourque, L. B. (2012). Communicating actionable risk for terrorism and other hazards $\star$.Risk analysis, 32(4), 601-615.

Yamasaki E. (2012) What We Can Learn From Japan's Early Earthquake Warning System. Momentum, 1(1), article 2. Produced by The Berkeley Electronic Press. Accessed 2016-06-12 at http://repository.upenn.edu/momentum/vol1/iss $1 / 2$

Zhao, X. (2009). Media use and global warming perceptions: A snapshot of the reinforcing spirals. Communication Research, 36, 698-723. 